\title{
Investigation of Harmonic Characteristics in Printer due to Different Types of Voltage Source
}

\author{
Risnidar C ${ }^{\mathrm{ab}}$, I. Daut ${ }^{\mathrm{c}}$, Syafruddin $\mathrm{H}^{\mathrm{ab}}$, Eddy Warman ${ }^{\mathrm{a}}$, Masykur ${ }^{\mathrm{a}}$, T. Kasim ${ }^{\mathrm{a}}$, Yusniati ${ }^{\mathrm{d}}$ \\ ${ }^{a}$ Electrical Engineering Department, Universitas Sumatera Utara, Medan, Indonesia \\ ${ }^{b}$ Faculty of Electrical Engineering University Malaysia Perlis, (UniMAP), 02000, Kuala Perlis \\ E-mail: risnidar@unimap.edu.my \\ ${ }^{c}$ Faculty of Electrical Engineering University Malaysia Perlis, (UniMAP), 02000, Kuala Perlis \\ E-mail: ismail.daut@unimap.edu.my,surya_et@yahoo.com \\ ${ }^{d}$ Faculty of Engineering University of Islam Sumatera Utara, Medan, Indonesia \\ Email:yusniati_27@Ymail.Com
}

\begin{abstract}
This paper discusses about harmonic characteristics due to different types of voltage sources. Usually, the voltage source is sinusoidal. But in actual condition the load that receives voltage sources through the elements where the output voltage of element as input to the load is not pure sinusoidal, for example voltage source at Power of Common Coupling (PCC) between transformer and linear load and nonlinear load. This research has been done with Schhafner Power Quality Analyzer and PM300 Power Quality Analyzer, was focused to all harmonic characteristics as power, voltage, current, power factor (p.f.), Harmonic Distortion, and harmonic energy losses cost. The load is printer because the printer is one of electronic device causes harmonics. The voltage sources in this research are sine wave, triangle wave and harmonic order combinations of $3^{\text {rd }}, 5^{\text {th }}$ and $9^{\text {th }}$. Why this research discuses voltage source for Harmonic order $3^{\text {rd }}, 5^{\text {th }}$ and $9^{\text {th }}$ and don not combination of $3^{\text {rd }}, 5^{\text {th }}$ and $7^{\text {th }}$, because the combination $3^{\text {rd }}, 5^{\text {th }}$ and $9^{\text {th }}$ is more complicated then combination of $3^{\text {rd }}, 5^{\text {th }}$ and $7^{\text {th }}$
\end{abstract}

Keywords — type of voltage source; power factor; energy losses cost; harmonic characteristics

\section{INTRODUCTION}

Ideally, the voltage sources at the end-user are sinusoidal. However, it is not quite possible to do for under a few conditions. The users usually get the voltage sources which are distorted from the fundamental in fact are considered as sinusoidal. Thus, this voltage waveform is actually a deviated from although it is from sinusoidal. This research focuses on the analysis of voltage source that is nonsinusoidal like that of square wave. At the same time the analysis of the voltage source created by combination of harmonic order 3rd, 5th and 9th is done. This harmonic order will produce a nonsinusoidal voltage source. If $3 \mathrm{rd}$ and 5 th are combined, they will produce nonsinusoidal voltage source which is called Harmonic 35. It is also true for other combination. These numbers show the order which is used to name the voltage source. The meaning of voltage source as harmonic 3rd, 5th and 9th combinations is voltage that is created by Schhafner Power Quality Analyser. Why this research discuses voltage source for Harmonic order 3rd, 5th and 9th and don not combination of 3rd, 5th and 7th, because the combination 3rd, 5th and 9th is more complicated then combination of 3rd, 5th and 7th This harmonic order will produce a nonsinusoidal voltage source. This research discusses the kinds of voltage sources used to serve the load, such as sine wave, square wave and the combination of the harmonics order, so it is necessary to discuss about Fourier series. To analyse the harmonics, application of the Fourier series is appropriate. The theory of Fourier series is complicated, but we shall see that the application of these series is rather simple because many discontinuous periodic functions of practical interest can be developed in Fourier series. [1][2]. Actually, Fourier series is a periodic function which can be written as sums of infinitely many sine and cosine functions of different frequencies [3] R.J. Beerends et al (2003), often expressed in terms of the angular frequency. Harmonic waveform distortion is one of the most important issues today.

The mathematic model of voltage sources are:

Sine wave, the mathematic model is:

$$
V_{s}=V_{\sin }=V_{\max } \sin (2 \pi f t)
$$


where:

$$
\begin{array}{ll}
\mathrm{V}_{\mathrm{s}} \quad= & \text { voltage source } \\
\mathrm{V}_{\text {sin }}= & \text { sine wave } \\
\mathrm{V}_{\max }= & \text { maximum voltage source setting. In this experiment } \\
& \quad \text { it take from } 160 \text { until } 220 \text { Volt } \\
\mathrm{f} \quad=\text { frequency fundamental in Hz } \\
\mathrm{t} \quad=\text { time in second }
\end{array}
$$

Square wave, the mathematic model is:

$$
V_{s}=V_{s q}=\frac{4}{\pi} \sum_{k=1}^{\infty} \frac{1}{h} \sin (h \pi t) \quad h=k-1
$$

Harmonic 35, the mathematic model is:

$$
V_{s}=V_{h 35}=V_{\max }[\sin (2 \pi f t)+\sin (3 \times 2 \pi f t)+\sin (5 \times 2 \pi f t)]
$$

Harmonic 59, the mathematic model is:

$$
V_{s}=V_{h 59}=V_{\max }[\sin (2 \pi f t)+\sin (5 \times 2 \pi f t)+\sin (9 \times 2 \pi f t)]
$$

In this research, the load is printer. Why this research choose load is printer, because the printer is one of nonlinear load. The most components in printer are electronics element which caused harmonic effects [4]. The presence of harmonic distortion in the applied voltage to a printer will both increase electrical losses and decrease efficiency. These losses will increase printer temperature, resulting in even further losses These currents passing through the system impedance cause voltage drops for each individual harmonic, resulting in distortion of the voltage's waveform. The effects of harmonic distortion of the voltage waveform due to impacts printer performance as p.f. IHD and THD for current and voltage, and energy losses due to harmonic. [5][6][7]

One of the main harmonic characteristics is power factor (p.f.). This is a measure of how effectively a specific load consumes electricity to produced work. The higher of power factor, the more work produced for a given voltage and current. The relationships vector between power and power factor to explain about power factor is shown in Figure 1. From Figure 1, the relationships between power and power factor for Linear Loads and Non-Linear Loads are as follow:

\section{A. Linear Loads}

$$
\begin{aligned}
p . f . & =\frac{P}{S}=\frac{k W}{k V A}=\cos \varphi \\
S & =\sqrt{P^{2}+Q^{2}} \\
k V A & =\sqrt{k W^{2}+k V A R^{2}}
\end{aligned}
$$

B. Non-Linear Loads

$$
\begin{gathered}
\text { p.f. }=\frac{P}{S}=\frac{k W}{k V A}=\cos \varphi \\
S=\sqrt{P^{2}+Q^{2}} \\
k V A=\sqrt{k W^{2}+k V A R^{2}+k V A R_{H}^{2}}
\end{gathered}
$$

True Power factor $=($ Displacement p.f $) \times($ Distortion p.f. $)$
The others characteristic of harmonic are: The values of Vrms Irms, Power (P), were calculated directly from the harmonic components obtained with a Fast Fourier Transform of the sampled data of the voltage and current waveforms of the printer under tests. These quantities were calculated as: [4][5][6][7]

$$
\begin{aligned}
& V_{r m s}=\sqrt{\sum_{h=1}^{\infty} V_{h}^{2}} \text { and } I_{r m s}=\sqrt{\sum_{h=1}^{\infty} I_{h}^{2}} \\
& P=\sum_{h=1}^{\infty} V_{h} I_{h} \cos \varphi_{h} \text { and } S=V_{r m s} I_{r m s}
\end{aligned}
$$

where $V_{h}, I_{h} \varphi_{h}$ are magnitudes and phase shift of the voltage and current, $h$ order harmonic.

The factor that measures the distortion in the non sinusoidal wave is Total Harmonic Distortion (THD) where this factor is defined for both voltage and current as below:

$$
T_{I}=\frac{\sqrt{\sum_{h=2}^{\infty} I_{h}^{2}}}{I_{1}} \text { and }{ }_{T H D_{V}}=\frac{\sqrt{\sum_{h=2}^{\infty} V_{h}^{2}}}{V_{1}}
$$

If $\mathrm{THD}_{\mathrm{V}}$ from each voltage source below $5 \%$ as IEEE Recommended Practices and Requirements for Harmonic Control in Electrical Power Systems Standard, the system do not need the filter.

\section{Methodology}

From the measurement of printer with Shaffner, where the voltage source to load is variable, and the models are: sinusoidal, square and a few harmonics waveforms. And the load is printer. These experiments are done, because to investigated the effect of voltage source type of harmonic to serve load. At any PCC in power system, the load maybe find the source not pure sinusoidal, for example from secondary of transformer. The main characteristic of harmonics are Individual Harmonic Distortion (IHD) for 3rd ,5th and 7th, Total Harmonic Distortion (THD) for voltage and current, Power losses due to harmonics, power factor, for each harmonics, $\mathrm{I}_{\mathrm{rms}}, \mathrm{V}_{\mathrm{rms}}$. The measurements are done with voltage sources variable from $160 \mathrm{~V}$ until $240 \mathrm{~V}$.
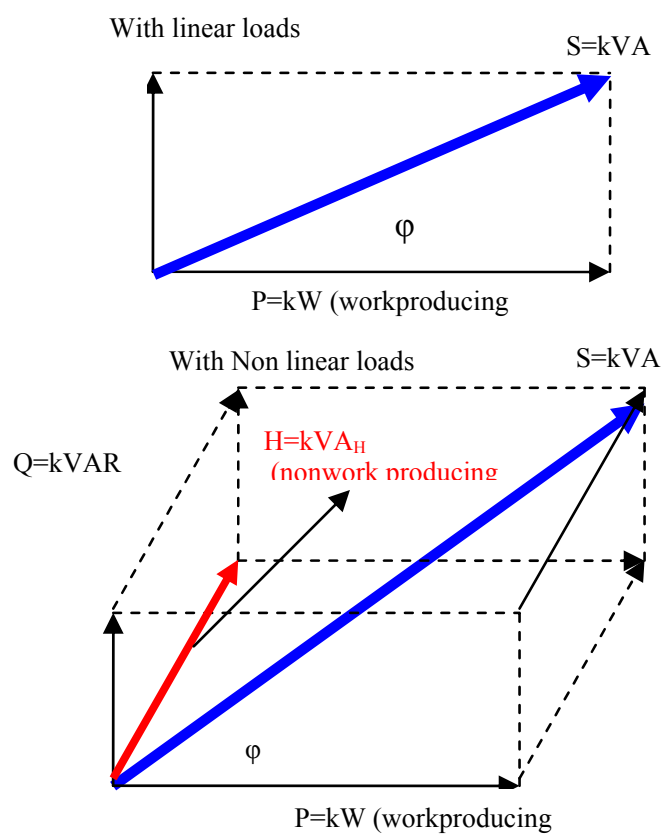

Fig. 1 Power factor relationship for Linear and Non-Linear loads 


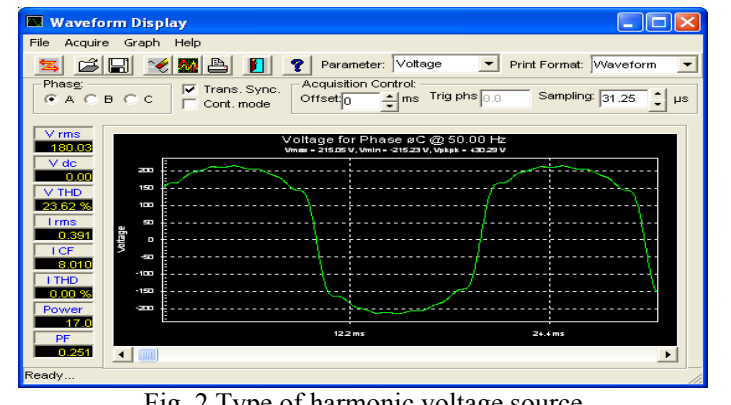

Fig. 2 Type of harmonic voltage source

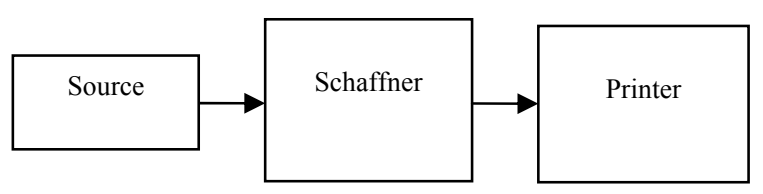

Fig. 3 Block diagram of measurement

The types of voltage source from the combination of harmonic order $3^{\text {rd }}, 5^{\text {th }}$ and $7^{\text {th }}$ as Fig. 2: The printer specification is printer model canon ip2770 as a non-linear load. In this research, the main characteristics of the printer were measured related to harmonic due to variable voltage source. The voltage sources from $160 \mathrm{~V}$ until $240 \mathrm{~V}$.

\section{DATA AND RESULT}

Data and result base on direct measurements of printer's model canon ip2770 as a non-linear loads and voltage sources at 240 Volt are as follow:
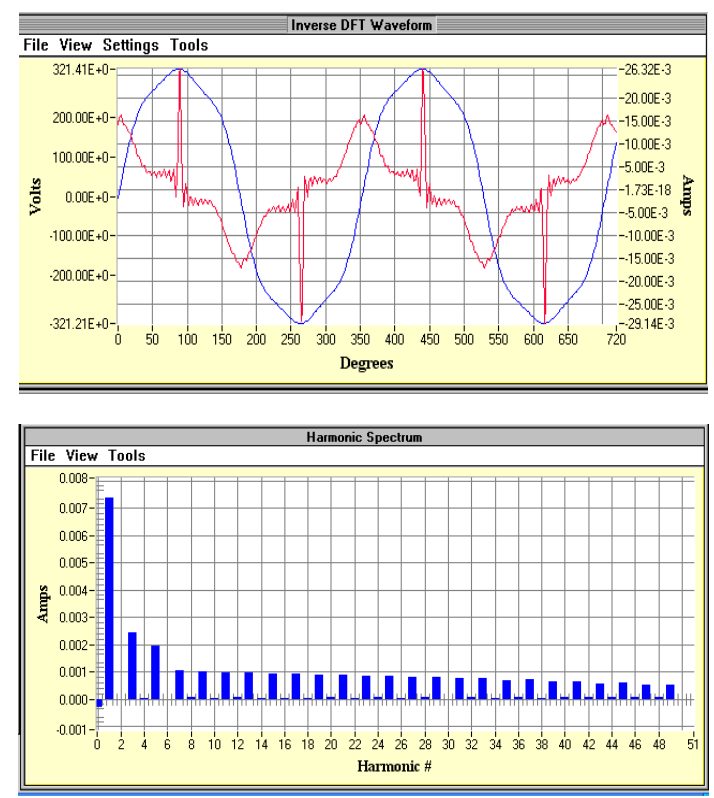

Fig. 4 Harmonic 35

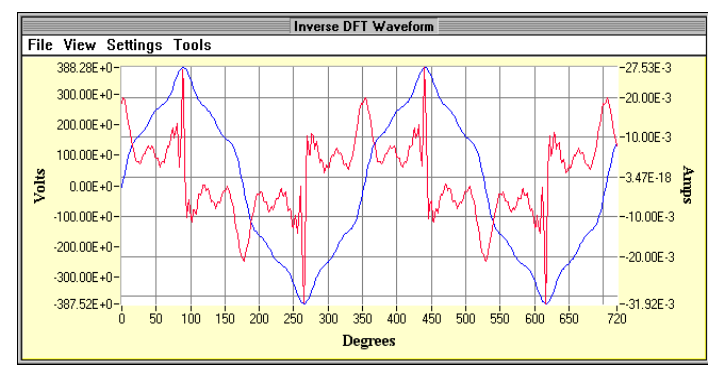

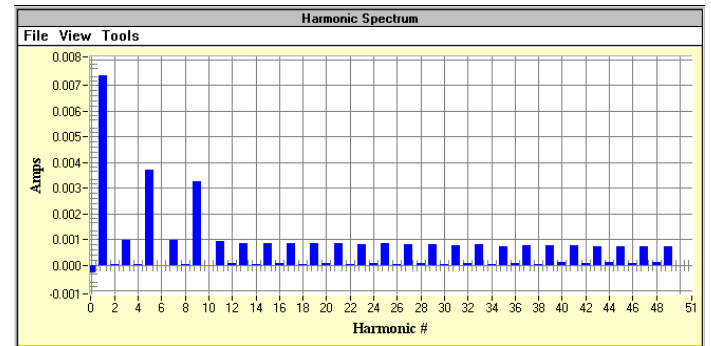

Fig. 5 Harmonic 59
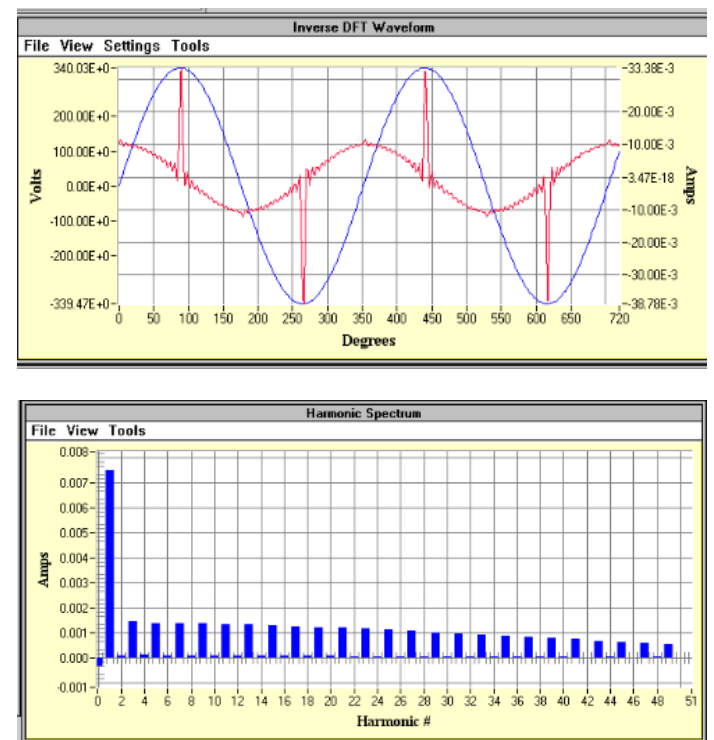

Fig. 6 Sine wave
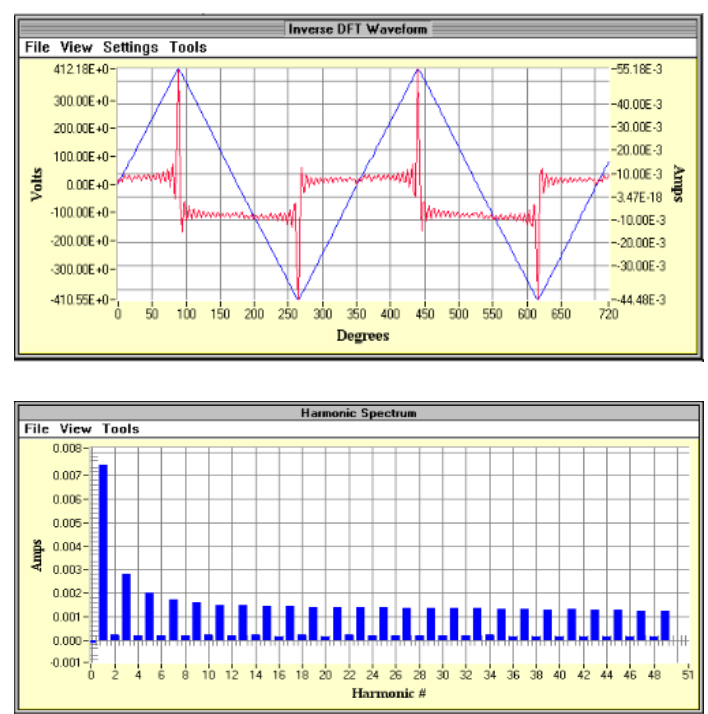

Fig. 7 Triangle wave

This research is focused analyse the influence of the voltage source types on harmonic characteristics as:

\section{A. Active Power}

The active power with voltage source triangle is largest $(0.419 \mathrm{~W})$, because for this waveform the distortion is high. And then is sinusoidal waveform $(0.335 \mathrm{~W})$. For harmonic waveform source, the harmonic $59(0.237 \mathrm{~W})$ is bigger than harmonic $35(0.223 \mathrm{~W})$. 
TABLE 1

HARMONIC CHARACTERISTIC OF PRINTER VS VOLTAGE SOURCE

\begin{tabular}{|l|c|c|c|c|c|c|}
\hline Voltage source & $\mathrm{P}(\mathrm{W})$ & $\mathrm{S}(\mathrm{VA})$ & $\mathrm{Q}(\mathrm{VAR})$ & p.f. & $\mathrm{THD}_{\mathrm{V}}(\%)$ & $\mathrm{THD}_{\mathrm{I}}(\%)$ \\
\hline Sine wave & 0.335 & 2.15 & 2.19 & 0.1512 & 0.257 & 33.13 \\
\hline Harmonic 35 & 0.223 & 2.135 & 2.123 & 0.1047 & 11.079 & 45.11 \\
\hline Harmonic 59 & 0.237 & 2.347 & 2.335 & 0.1010 & 9.913 & 53.67 \\
\hline Triangle & 0.419 & 2.62 & 0.002583 & 0.16 & 11.94 & 51.93 \\
\hline
\end{tabular}

\section{B. Apparent Power}

The apparent power with voltage source Harmonic 35 is smallest (2.135VA), because for this waveform the distortion is high. And the triangle waveform is highest (2.62VA).

\section{Reactive Power.}

The reactive power with voltage source Harmonic 35 is smallest (2.123VAR) closely to Sine wave, because for this waveform the distortion is high. And the triangle waveform is highest (2.583VAR). The voltage source Harmonic 59 nearly to the triangle wave.

\section{Power factor (p.f.)}

The power factor (p.f) with voltage source triangle waveform is largest (0.16), because for this waveform the distortion is high. The sinusoidal waveform (0.1512) is follows. For harmonic waveform source, the harmonic 35 is largest $(0.1047)$ and then the harmonic $59(0.1010)$

\section{E. THD harmonics voltage.}

The THD from sine waveform voltage source Vs voltage harmonic experiment showed that the $\mathrm{THD}_{\mathrm{V}}$ with voltage source Harmonic 35 has the largest distortion (about $11.079 \%$ ), because for this waveform the distortion is high, and the smallest distortion is sine waveform $(0.257 \%)$. Only a voltage source from sine wave that meet IEEE Standard (below 5\%).[8]

\section{F. THD harmonic current.}

$\mathrm{THD}_{\mathrm{i}}$ with the sine wave is small distortion (33.13\%), because for this waveform it is as fundamental waveform. The voltage source Harmonic 59 is largest (53.67\%), because for this waveform the distortion is high.

\section{CONCLUSION}

From analysis we can be drawn the conclusions as follows:

1. Power (active, apparent and reactive) due to various voltages is highest for Triangle wave. For active power the second is Sine wave, but for reactive power the second is Harmonic 59.

2. Power factor for Sine wave is nearly to Triangle wave, while Harmonic 59 is smallest.

3. The THD harmonic voltage from Sine wave has a small distortion and it is followed by harmonic 59, harmonic 35, while Triangle wave is biggest.

4. The THD harmonic current due to Sine wave is smallest but Harmonic 59 bigger than triangle.

\section{ACKNOWLEDGMENT}

The authors would like to express their gratitude to the Fundamental Research Grant Scheme (FRGS), School of Electrical System Engineering of Universiti Malaysia Perlis (UniMAP) and Power Electronics and Electrical Machine Design Research Cluster provide for research facility respectively.

\section{REFERENCES}

[1] Charles K. Alexander N.O. Sadiku, "Fundamentals of electric circuits", 4th Edition, International Edition, Mc Graw Hill , 2009

[2] Erwin Kreyszig, "Advanced Engineering Mathematics" Wiley International Edition, 9th Edition, John Wiley \& Sons, 2006

[3] R. J. Beerends, H. G. ter Morshe, J. C. van den Berg and E. M. van de Vrie, "Fourier and Laplace Transforms", Translated from Dutch by R.. J. Beerends, Cambridge University Press, 2003.

[4] Peter Bechard, "Fault ZoneAnalysis POWER QUALITY", The 2004 Motor Reliability Technical Conference, PdMA Corporation.

[5] Barry W. Kennedy, POWER QUALITY PRIMER, McGraw-Hill, Singapore, 2000

[6] Francisco C. De La Rosa, "Harmonics and Power Systems", Taylor \& Frencis, CRC, Boca Raton, 2006.

[7] J. Arrilaga, B.C.Smith, N.R. Watson, A.R. Wood, POWER SYSTEM HARMONIC ANALYSIS, John Wiley \& Sons, Singapore, 2000

[8] IEEE Recommended Practices and Requirements for Harmonic Control in Electrical Power Systems 